\title{
BM Relation Axiom - 3. Quadrant - the First Phases of Business Model Innovation in a Network-based Business Model Innovation Situation
}

\author{
Peter Lindgren* and Jesper Bandsholm
}

\author{
Aarhus University, Department of Business Development \& Technology, \\ Birk Centerpark 15, 7400 Herning, Denmark \\ E-mail: \{peterli; bandsholm\}@btech.au.dk \\ * Corresponding Author
}

Received 1 September 2016; Accepted 20 October 2016;
Publication 25 November 2016

\begin{abstract}
The BM relation axiom was presented as a conceptual framework [12] as a way to view how specific relations in business models (BM) and between BMs are related, when seen from 4 different perspectives - viewpoints. The research paper verify how the way business models, both intern- and externally the business, relate to one another changes in respects to the phases of the business model innovation (BMI) and the phases of the business model development in a new BM Ecosystem [13].

Previous research has covered the first and second quadrant of the relation axiom, where this paper focuses specifically on the third quadrant of the relations axiom - outside the business - in the first BMI phases; bubble, idea and concept. A case of network-based business model innovation (NBBMI) is in focus and will take the reader through the process from just after the first mutual agreements [13] have been made in the network of businesses to develop a sustainable energy plant where Businesses BMs are supposed to operate in symbiosis to the next phase - scenario conceptualization phase. The study is based on the research from 2012 to 2015 of the GreenLab Skive network-based business model (NBBM) case involving 12 independent businesses.
\end{abstract}

Journal of Multi Business Model Innovation and Technology, Vol. 4_2, 71-88.

doi: 10.13052/jmbmit2245-456X.423

(c) 2016 River Publishers. All rights reserved. 
NBBMs and NBBMI outside the business are in the relation axiom placed in the third quadrant of the relation axiom, where the network of BMs and their value exchange through their BMs relations to one another is particularly in focus. The paper shows the network setup and the relations between the involved businesses' BMs within the network in the three different phases of the NBBMI case GreenLab Skive.

Keywords: Business Model Relation Axiom, Business Model Cube, Business Model, Business Model Innovation, Business Model Language, Networkbased Business Model innovation.

\section{Introduction to the Business Model Cube?}

Joint action, value and knowledge sharing in networks are fundamental and becoming a more and more important aspects of business model innovation (BMI) for businesses to meet increasing demands of more complex and fast growing requirements of business performance, that in many ways can be solved through network-based business model innovation (NBBMI). NBBMI with network partners that often aren't familiar with each other is an increasing challenge for businesses internationally, since this type of partnerships unlocks new competences, markets and enables unique value propositions.

12 independent businesses initially joined this NBBMI project in 2012 regarding the establishment of a new concept of a dynamic and multi-source energy plant, where the involved businesses had to work in symbioses from the very first moment of operation. This paper begins, when the businesses has reached the second phase of the NBBMI project, where they are to finalize and close the conceptual phase.

In a previous paper presented at the IFKAD conference 2015 the GreenLab Skive (GLS) project was in the initial and "happy days" of the NBBMI project, characterized by early excitement and visionary mindsets. The second phase is characterized by feasibility, negotiations and alignment of expectations. Additionally, this phase brings the interest of external network partners, trying to make their way into the BM Ecosystem of the GLS project with their offerings. This has a significant impact on the GLS project - both positive and negatively.

Current BM science and best practice tools presents very little literature upon networks and value exchange aspect of NBBMI projects - particularly the BM relation axiom topic. The NBBM reflects the 3. quadrant in the relation axiom [12] as seen in the relations axiom model beneath. 


\section{Introduction to the Relation Axiom}

For many year's perception, action and cognition of network partners in a BMI project have been studied without investigating the real roles of network partner's BM's relations and real value interactions related to BMI seriously. Most likely because there previously haven't been a tool or framework to do so.

However, the establishment of a perspective for BM's relations is essential both at the very first moment of the meeting between the involved participants who these days are more often different and unknown to each on another because of the increase in NBBMI and interdisciplinary BMI projects. But as we show in this paper, this is also the case in the later phases of the BMI process, when the relations really take form and becomes manifold through the conceptualizing phase. When it comes to knowledge sharing and learning throughout the BMI project's lifetime, relations are key factor of the "to-be" $\mathrm{BM}$, since the creation and strength of relations often are the foundation of a successful and even implemented BMI project.

However, as we show in previous papers $[12,13]$ external BM Ecosystems and the focal BMI system's own BM Ecosystem dimension in itself can cause some serious barrier and challenges for progression, even though the relations within the BMI network is well established and functioning.

This paper aims to understand the relation mechanisms "at the later moment of a network based BMI process" supporting participants' ability and motivation to act together with each other in a BMI project that have already taken off. The study is a new BMI study on NBBMI related to the 3. quadrant of the relations axiom [12], where BMI takes place outside the business and outside the business model in focus (within the network).

The paper address relations in high risk and sensitive areas of BMI, where businesses open their core business, core BM and core competences - and relate these for the common GLS project. The paper address one longitudinal case research study of a NBBMI project started in 2012 - the Greenlab Skive project - http://www.greenlabskive.dk/.

\section{Design/Methodology/Approach}

The paper provides one case study in one high-risk and complex BMI project and BM ecosystems. The research methodology was case research carried out from 2013 to 2016. The research was carried out as participative observation and registration with support of special developed BMI tool for BMI relations mapping. 


\section{The Business Model Cube and the Multi Business Model Approach}

The paper builds upon the framework of the business model cube [12] and its seven dimensions equivalent to the overall model we propose of how any business is constructed.

The business model cube refers to: "How a certain business model in the business is constructed and actually operates - an "as-is" BM - or is intended to be constructed and operate - a "to-be" BM related to the seven dimensions: value proposition, user and/or customers, value chain functions, competences, network, relations and value formula.

The seven dimensions should be taken into consideration by any business that is interested in running its operations well. However, there is a difference between the way businesses want to run their operations - seven fictional dimensions of a business and how a business really runs its operations. By mapping empirical data on several businesses from our business case studies to the seven dimensions, we found that most businesses actually have more than one business model. In other words, the businesses they described via the seven dimensions are different to how they actually run their business models. Some of these business models were close to their original description of the seven dimensions but others were different - defined as the multi business model approach [12]. This, among other, gives the basis of the relations axiom.

We argue therefore that a business' cannot be explained by just one BM, "the core BM", but would with preference be better to be explained by different BMs. However, still each with seven generic dimensions, but with different characteristics - dimensions and components. In our research, we only found Casadesus-Masanell [5] and to some extent Markides [14], who indicates the existence of more BMs within a business.

As a consequence, we propose that a business can be said to have one or more BMs related to different business cases - the multi-business model approach [11]. However, any of these BMs can be defined as related to a generic BM concept consisting of seven generic dimensions. Some BM in the business are already operating (AS IS) and some are under construction (TO BE).

Businesses BM are related through tangible and intangible relations [1, 16-18], to other businesses BM's - customers, competences and networks [2, 10, 19]. Businesses BM's are related through strong and weak ties [8]. Businesses send their BM's value propositions to other businesses' BMs through these relations (Lindgren 2013) - receiving and consuming value 
To Be

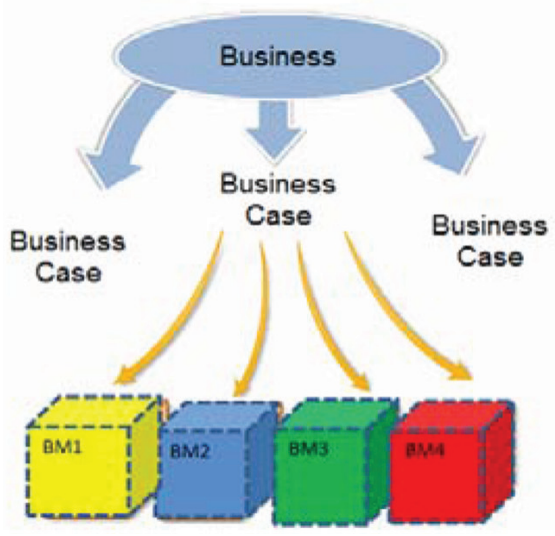

As Is

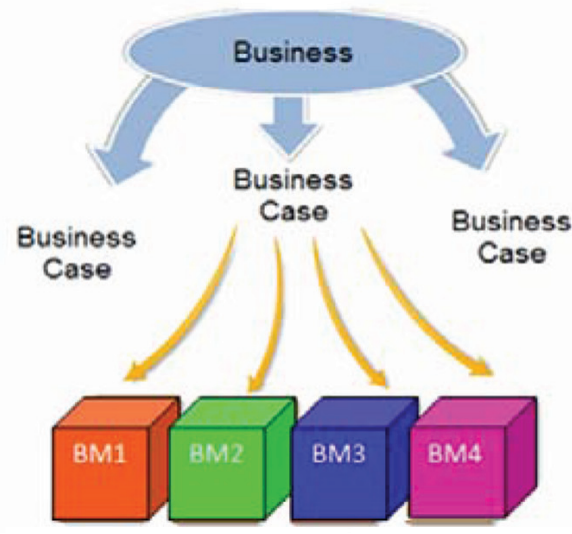

Figure 1 The Multi Business Model approach related to "to-be" and "as-is" BMs.

propositions. Relations can be one-to-one, one-to-many or many-to-many. Relations can be visible and invisible to humans or machines [11].

Tangible and intangible relations are used in the business to deliver values [1]. Businesses relate their value proposition, users/customers, value chain functions, competences, network and value formula through relations [12].

Relations are used in any BM and between BM's for creating, capturing, delivering, receiving and consuming values. Very few BM frameworks include relations and most BM frameworks do not regard relations as "the media" or "carrier" of value. Osterwalder e.g. do not use the relations as an active building block that has the capability to carry and transfer value in a BM but just acknowledge that relations exist. Osterwalder [15] acknowledges customer relations as important and the business is related to customers but seems to forget/ignore relations to suppliers and other stakeholders - networks in the BM.

Neither are the relations to competences in the BM focused - competences that enables value creation and capturing together with consumptions.

We found only very few $[1,5]$ that go into visualizing and documenting value transfers through relations in BM. We found that a BM without relations between the BM dimensions will be interlocked and thereby not able to operate (create, capture, deliver, receive, consume) and thereby become an operating "as-is" BM. Beneath is a sketch illustration of different relations inside a BM but as we will see later in the case of GLS the relations map is more complex. 


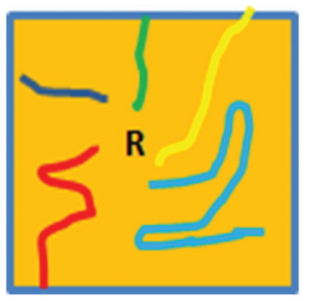

Figure 2 The Relation dimension (Lindgren 2013) [12].

\section{The Relation Axiom and Relation within the Business Model Cube}

Research [11] shows that it is highly valuable for businesses to thoroughly know their own businesses' "as-is" and "to-be" BM relations - first in a self-transcending (ideal state) way, because it preliminarily indicates that the awareness, strength, weakness, opportunities and threats of the business own tangible and intangible relations. This is present in the "download" phase and if followed by the "seeing" phase of a business BM's relation in the BM relations axiom this can be shown as sketched in Figure 3.

In our research, we found four sets of relations - or viewpoints - that are of importance to BMs and should be attended to by business managers.

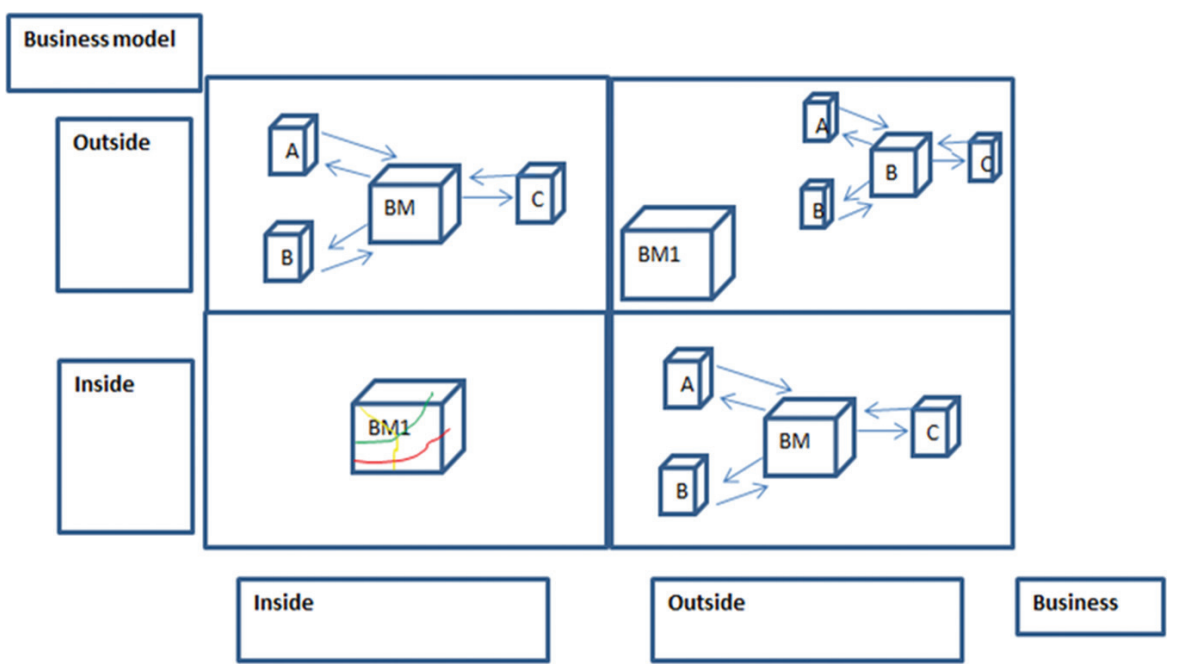

Figure 3 The Relationship Axiom of a business BM (Lindgren and Horn Rasmussen 2012) [11] inspired by Verna Allee [1], Martha Russels [19] and Debra Amidon [10]. 
1. In first quadrant - "inside BM, inside business" - the BM's internal relations between the six BM dimensions of a given BM are mapped. These relations express the inner logic and value transfer between the dimensions of the BM, that among others secure communication.

2. In second quadrant - "inside business, outside BM" - the BM's external relations to other BMs inside the same business are mapped. These relations express the external logic and value transfer between different BMs and their dimensions in the business, describing the interrelation and - connection of the BM as addressed earlier.

3. In the third quadrant - "inside BM, outside business" - the BM's relations to other external businesses' BMs are mapped. These relations express the outer logic and value transfer between different BM's dimensions from the $\mathrm{BM}$ in focus to BMs outside the business - often acknowledged as network partners and/or BM Ecosystem.

4. In the fourth quadrant - "outside BM, outside business" - the BMs that currently doesn't have a relation(s) to external BMs or an BM Ecosystem outside the business are mapped here. These relations express the outer logic and value transfer between different BM's dimensions outside the business, which the business and its BMs are not (yet) part of.

The relation axiom is meant to give four perspectives or viewpoints of a $\mathrm{BM}$ and can be used on any BM in the business. The relation axiom can be used both for "as-is" and "to-be" BMs. In this paper the third quadrant is in focus.

In combination with a focus on both the tangible and intangible relations in the different quadrants of the relations axiom can show business- and BMs innovation opportunities to release more value, reduce cost and construct the $\mathrm{BM}$ differently in a relation perspective.

The ability to act on potential relations, see and sense potential relations can enable even higher potentials - hidden values and intangible values. This therefore addresses the challenge and dilemma of business knowing of their "as-is" and "to-be" BMs' relations related to running and developing their business and related BMs - but not being able to know how to act upon these existing and potential BM relations.

Values of a BM can be seen in a broader perspective than many BM frameworks do today. As each partner's BM's relation to users/customers, competences and networks in the inter-organizational network of relations if "as-is" and "to-be" BMs operates and are being created they value each other. Why? Because value and cost are strongly interrelated with relationships (Blois, 2004). Attributes of relations - or in our framework - components of 
a relation - are related to the relationship between the partner's BMs - either it is e.g. a simple trade "as-is" BM or a BMI project "to-be" BM - where values (products, service and processes) are still not necessarily defined -. Therefore it is necessary to say, that relations also influence each other and are in some sense interrelated. However we do not yet know much about this interrelatedness of relations.

As seen earlier, the value equation is not only related to products, services and processes but is also strongly connected to the relations and thereby a result of the relation between BMs in either a trade or a BMI project. In previous paper [12], we only cover the internal relations - the "inside BM, inside business" relations - within a BM.

Relations, activity links, resource ties, and actor's bonds $[3,7,9,10]$ are all tools used to describe and map relations.

The creation, capturing, delivering, receiving and consumption of value is enabled through relations [6, 11]. Relations connect the different BM dimensions' components and enable the creation, capturing, delivering, receiving and consumption processes of value. However, if any BM is not able or "willing" to send and receive the value through the relations, then the relation has no value and no task.

Having verified previously academically that the seven dimensions of the BM exists [12], it enables us to complete the concept of the BM Cube. In a 2D picture and with the seven dimensions spread out flat it would now be possible to map the relations in a BM and see what they look like and potentially could look like, as illustrated on Figure 4.

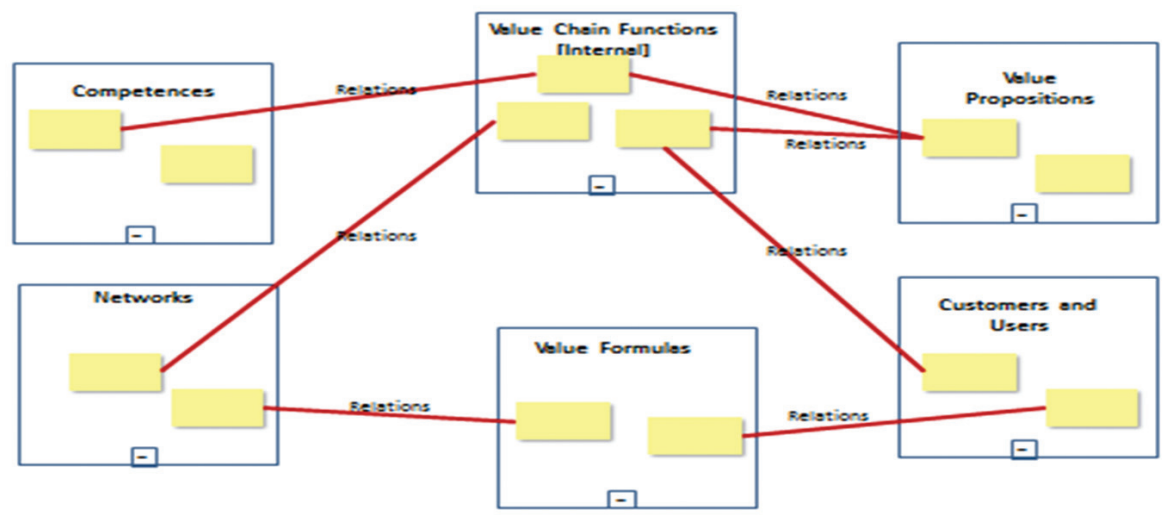

Figure 4 The seven dimensions of the Business Model cube in a $2 \mathrm{D}$ presentation (Lindgren 2013) [12]. 

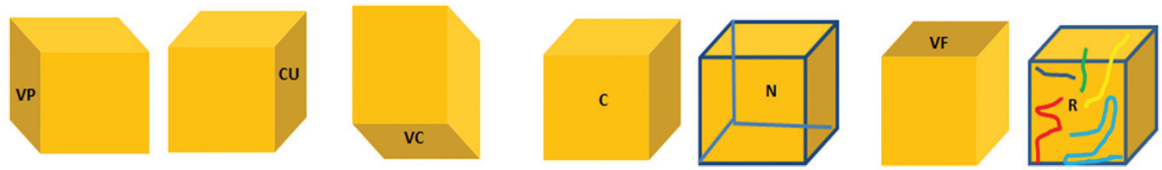

Figure 5 The seven dimensions of the Business Model Cube presentation and a sketch of the "inside BM, inside business" BM relations in a BM cube (Lindgren 2013) [12].

Accordingly, we discovered that the seven dimensions form a BM Cube with the "inside BM, inside business" relations inside the Cube as shown in a sketch model in Figure 5.

The 2D version is very helpful when working on a BM dimension level, where a 3D version would be even more helpful when working with relations of BMs, BM portfolio, business and BM ecosystem level. This we hope to establish in more detail in future research in our MBIT Lab.

Summing up from the above mentioned, we propose that any BM cube consists of seven dimensions - six sides and the BM relations inside the BM cube that interconnects all other dimensions and components together and enables creation, capturing, delivering, receiving and consumption of values. We illustrated the BM Cube in Figure 6 [12].

\section{Business Case: GreenLab Skive}

In order to approach the relation axiom in the 3. quadrant of a business and its related BMs a case study of the GreenLab Skive is presented.

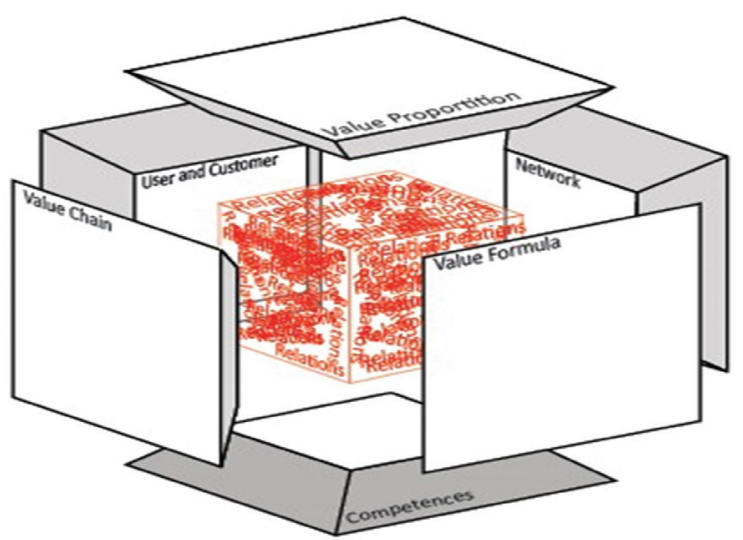

Figure 6 The Business Model Cube [11]. 


\section{GreenLab Skive (Appendix 1)}

GreenLab Skive is a state of the art power-2-gas (P2G) production plant under development in the central region of Jutland in Denmark, with an estimated budget of 140 million euro. GreenLab Skive is unique and characterized by its dependencies upon the BMs of the network partners, being; 1 Municipality, 2 Universities and 7-9 businesses and up to 4 external consultancies. In order for GreenLab Skive to succeed, it is highly reliant upon a network-based business model (NBBM) that can unite the partners into symbioses. This puts an emphasis on the 3. quadrant of the relation axiom, where relations between a BM and BMs outside the business - the network - is in focus.

\subsection{The Development of GreenLab Skive}

The development of GreenLab Skive (GLS) will be presented over three phases; Bubble, Idea and Concept. Each phase will present the current state of the project on a conceptual business layer of GreenLab Skive, a business layer of the businesses' BMs and a layer for the NBBM of GreenLab Skive as illustrated in Figure 7 and in more details in Appendix 2.

\subsubsection{GreenLab Business BMs}

Each of the businesses came into the GreenLab Skive (GLS) collaboration with a series of BMs in mind in the bubble-phase, that they saw as relevant and/or interesting to activate upon GLS based on the original description and vision. As the development of GLS progressed into the idea-phase, the description, and maybe even vision, of GLS changed and the intended BMs needed to be adapted, swapped or even removed from the project. Even whole businesses had to leave the BMI project. In the case of GLS, one of the originally participating businesses quit the project due to strategical and organizational mismatches.

\begin{tabular}{|c|c|c|c|}
\hline & Bubble & Idea & Concept \\
\hline GLS NBBM & $=$ & $\begin{array}{l}=\square= \\
=\square= \\
=-\bar{L}=\end{array}$ & 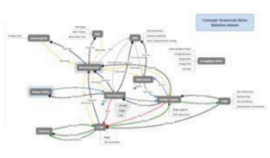 \\
\hline
\end{tabular}

Figure 7 The 3. Quadrant of the relations axiom seen in 3 phases of the BMI project GreenLab Skive. 
However, this also leaved an opening for new and/or alternative Businesses and BMs, that was not first thought of as relevant or interesting. This development over time is an essential discipline of doing open business model innovation and BMI, since especially NBBMs chases synergies, that can often can only be achieved in tight collaboration with a series of external businesses and their BMs.

Many of the businesses had not previously done business together and they barely knew each other before entering the Greenlab Project. Therefore, only the individual business itself knew about their own portfolio of BMs and which one was relevant and/or interesting in relation to GreenLab Skive. This also meant, that every time some of the network partners introduced a new $\mathrm{BM}$ or change to an existing BM or the common NBBM, the business itself needed to sense if the role of a specific BM was changed and the BM needed to be adapted to the new circumstances - making the BMI process very dynamic and emphasised the change over time.

\subsubsection{GreenLab Skive NBBM}

Seen from this perspective the development of GreenLab Skive became more and more complex and interrelated - as shown in the 3 phase - concept phase in Figure 7. The further the process gets, the more involved and related BMs are discovered. Relations between businesses BM's in Greenlab Skive, shown as a complex value stream enabled by the growing numbers of established tangible and intangible relations in the different BMI phases can be seen in larger and more detailed scale in Appendix 2.

In the bubble-phase the infant idea of GreenLab Skive is shown with its fundamental components linked together on a technical resource level. As the case moves into the idea-phase and more businesses shows their interest in the project the network of businesses develops their BM relations into a more and more concrete BM idea version and an increasing complexity of relations becomes present.

After the workshop with the involved businesses and a review of their BMs of interest in respect to GreenLab Skive a concept-phase scenario was created. This step first of all assigned the different businesses with certain elements of the NBBM, but also gave an even clearer indication of how the businesses wanted to do business with one another - and thereby how they wanted to be related with their BM's. Many of the businesses had several BMs involved in the NBBM. This has not been illustrated in our figures in this paper - some since they are inside the individual business (2. Quadrant in 
the relations axiom) - which is not the focus of this paper - but others because they were still too intangible relations to map this way.

The mapping also showed that a NBBM isn't just businesses BM's linked together, but it truly consists of a strong interrelated network and interactions between multiple BMs from each of the businesses, that exchanges value over time and are expected to exchange value over time.

\section{Discussion}

The inspiration for the relation axiom has evolved through our research on top of the increasing business model, relations literature and practice in Business Model research. The concept of relation axiom emerged from the research and test in several business model cases (Appendix 1) and was further developed in the study of GreenLab Skive related to the Biogas2020 project (Biogas2020). Today, BM is argued to be a general model for how any business runs its business. Conversely, this paper argues that no business has only a single BM that makes up their business. Businesses have more BMs that have many relations to and are in relation with other businesses' BMs inside and outside their own business - the relation axiom. This paper addresses the concerns dealing with the different views upon how one BM relates to other BMs: "inside-in", "inside-out", "outside-in" and "outside-out" quadrants of the relations axiom. The focus of this paper has been the "outside-in" - the 3. quadrant - presented particularly through the "to-be" BM of GreenLab Skive.

The research furthermore addresses the gap in research and strong demand to find a generic definition and language of relations related to BMs in network. Until now most BM frameworks use the relations term in BM as a no active dimension and as a kind of "facebook relations" approach. Many BM frameworks do not take notice of whether the relations actual is critical and is vital to the BM's "logic" and "life". Further they do not see relations as "medias" and/or "pipelines" for tangible and intangible value exchange.

In the Greenlab Skive case we were able to observe how the business constructed a NBBM and how they intended to relate their BM's in a future operating Greenlab Skive business. Also we were able to observe the relations and value transfer during the BMI process from bobble phase to concept phase. 


\section{Conclusion}

The research work is related to the yet limited "world of BM's relations" and the enormous BMI possibilities of BM's relations - both related to value and cost of relations, but also to the creation and interaction between Businesses $\mathrm{BMs}$ relations during the NBBMI process. Once we fully understand the levels and functions of relations in BM's - the dimension and components of the BM relations - thoroughly and are able to communicate, work and innovate with $\mathrm{BM}$ relations at all of these levels - then we have released the real potentials of BM's and BMI. In this context, we proposed that BM relation - both tangible and intangible relations - are related to the other six dimensions of The Business Model Cube; value proposition, user and/or customer, value chain functions [internal], competence, network and value formulae.

The GreenLab Skive case study showed the relations axiom framework in practice with the 3. quadrant "outside-in" in focus. Examples from the Greenlab Skive case verify that the "outside-in" relations exists and are a central part of NBBMs outside the business.

Conceptually, the relations axiom was formed on behalf of the framework of the BM Cube and its seven dimensions and could be very useful to better understand the potentials and constraints of NBBMI.

\section{Future Expected Results/Contribution/Acknowledgement}

The study has enlightened a strong demand for further research and testing of the concept of Relations Axiom and framework in more businesses, more use cases and samples. The next step has been initiated - a larger quantitative and qualitative empirical-based research to clarify more details of the relations axiom. The tests are intended to be a part of a larger EU and US funded research project together with establishing several relations axiom test in our MBIT Lab.

We acknowledge EU Interreg Biogas 2020 [4] for enabling us to study the case of Greelab Skive.

\section{Appendix 1 - List of Businesses Tested with the BM Cube Framework and the 7 Dimensions}

\section{Primary case in this paper}

GreenLab Skive 


\section{P. Lindgren and J. Bandsholm}

\section{Secondary cases for this paper}

EV Metalværk A/S, Censec, AU Library, Aarhus Lufthavn, Vlastuin, HSJD, E 45, Herning Kommune, Larla,

\section{Appendix 2 - GreenLab Skive Case}
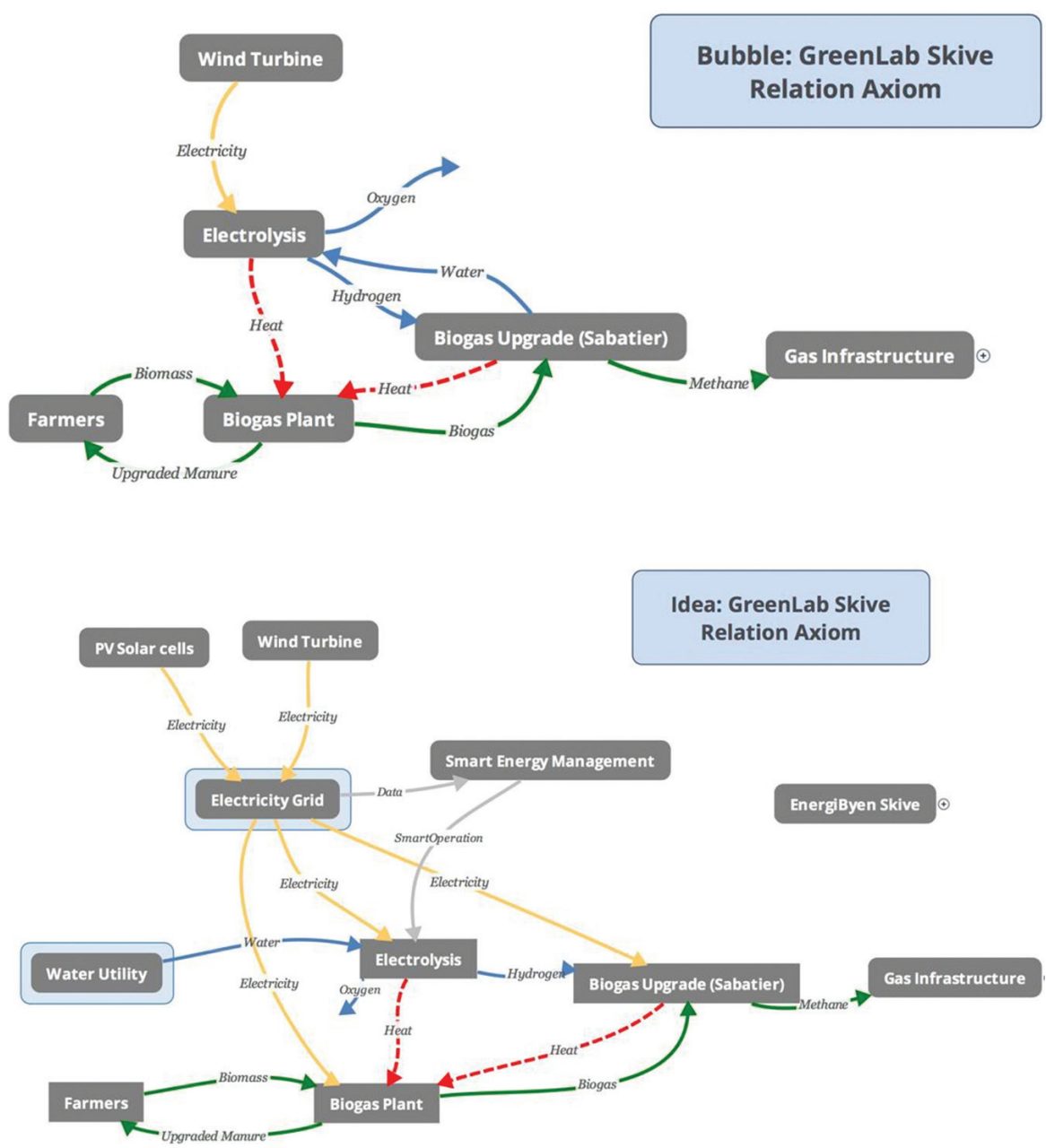
BM Relation Axiom - 3. Quadrant - the First Phases of Business Model 85

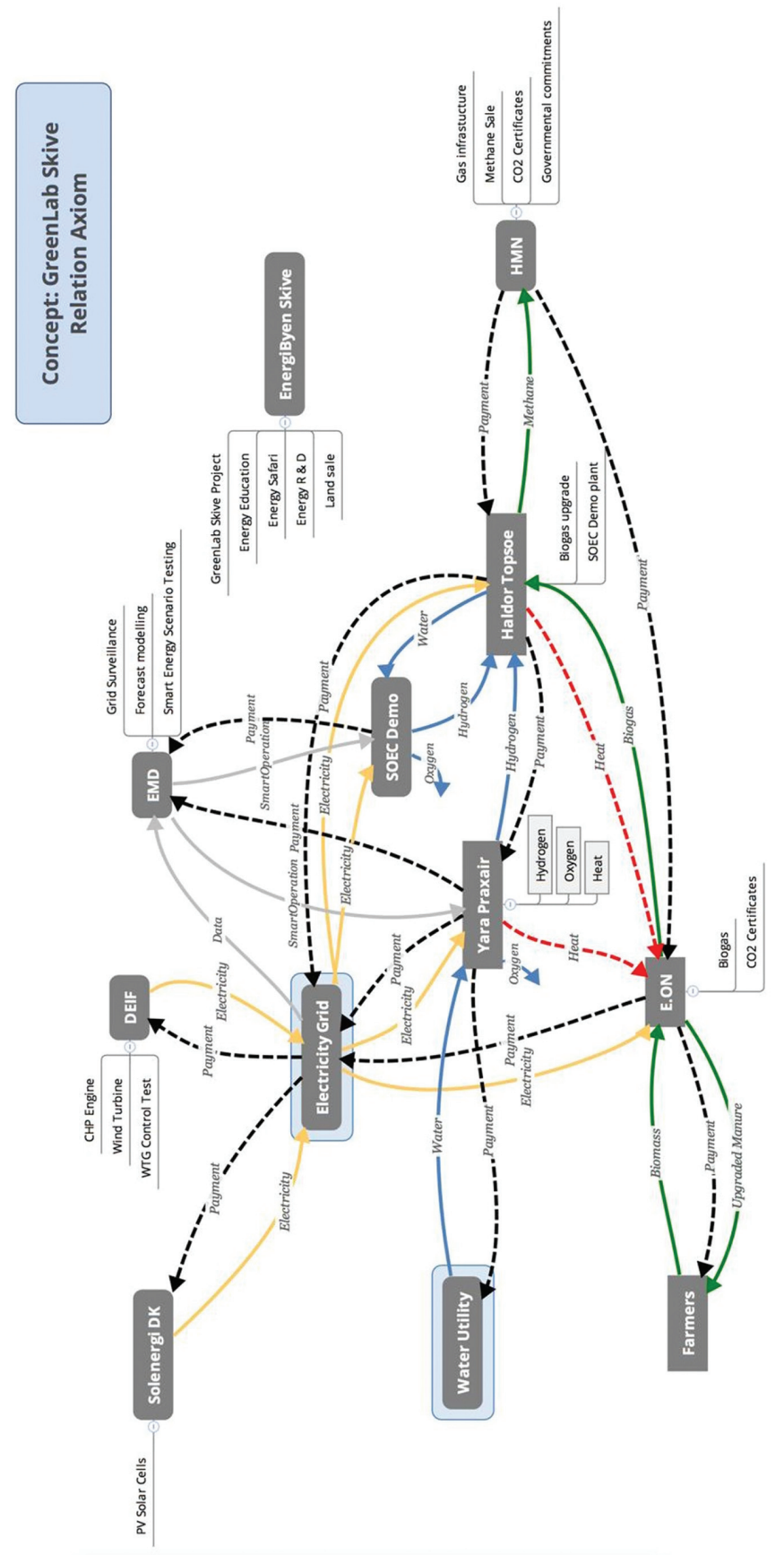




\section{References}

[1] Verna, A., and Schwap, O. (2011). Value networks and the true networks of collaboration. Available at: http://www.valuenetworksandcollaborat ion.com/

[2] Amidon Debra, M. (2008). Innovation SuperHighway Amidon, ISBN13: 978-008-049-156-1. Netherlands: Elsevier Science.

[3] Axelsson, B., and Easton, G. (Eds.). (1992). Industrial networks: a new view of reality, Vol. 11. London: Routledge.

[4] Biogas2020. European Intereg project. Available at: http://translate. google.com/translate?hl=sv\&sl=sv\&tl=en\&u=http://www.biogas 2020 . se/event/\&sandbox=0\&usg=ALkJrhgk3IvI_bymaZtFFgv7nwtUDJc_mw

[5] Ramon, C.-M., and Ricart, J. E. (2010). From strategy to business models and onto tactics. Long Range Plan. 43, 195-215.

[6] Coviello, N. E., Brodie, R. J., Danaher, P. J., and Johnston, W. J. (2002). How firms relate to their markets: an empirical examination of contemporary marketing practices. J. Mark. 66, 33-46.

[7] Day, G.G. (2000). Managing market relationships. J. Acad. Mark. Sci. 28, 24-30.

[8] Granovetter, M. S. (1973). The strength of weak ties. Am. J. Sociol. 78, $1360-1380$.

[9] Håkansson, H., and IMP Group. (1982). International marketing and purchasing of industrial goods: an interaction approach. Chichester: Wiley.

[10] Håkansson, H., and Snehota, I. (1990) No Business is an Island: the network concept of business. Scand. J. Manage. 5, 187-200.

[11] Lindgren, P., and Rasmus, J. (2012). Towards a multi business model innovation model. J. Multi Bus. Model Innovat. Technol. 1, 1-22.

[12] Lindgren, P. and Rasmussen, O. H. (2013). The business model cube. J. Multi Bus. Model Innovat. Technol. 1, 135-180.

[13] Lindgren, P., Aagaard, A., and Ulldall, L. (2015). "How to establish knowledge sharing from the very first moment in critical and risky business model innovation project," in IFKAD: International Forum on Knowledge Asset Dynamics. Palace Hotel, Italy.

[14] Markides, C., and Charitou, C. (2004). Competing dual business models: a contingency approach. Acad. Manage. Execut. 18, 22-36.

[15] Osterwalder, A., and Pigneur, Y. (2010). Business model generation. New Jersey: John Wiley \& Sons, Inc.

[16] Provan, K. G. (1983). The Federation as an interorganizational linkage network. Acad. Manage. Rev. 8, 79. 
[17] Provan, K. G., Fish, A., and Sydow, J. (2007). Interorganizational networks at the network level: a review of the empirical literature on whole networks. J. Manage. 33, 479-516.

[18] Provan, K. G., and Kenis, P. (2008). Modes of network governance: structure, management, and effectiveness. J. Public Admin. Res. Theory, $18,229-252$.

[19] Russels. (2012) Presentation Stanford University 2010 at the EU and US FinES Conference on Emerging Business Models. Available at: http://www.youtube.com/watch?v=RrEi-gval78. Denmark: River Publisher and Russels Martha.

\section{Biographies}

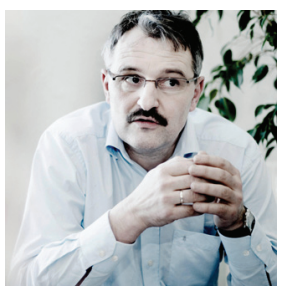

P. Lindgren Ph.D, holds a full Professorship in Multi business model and Technology innovation at Aarhus University - Business development and technology innovation and has researched and worked with network based high speed innovation since 2000. He has been head of Studies for Master in Engineering - Business Development and Technology at Aarhus University from 2014-2016. He is author to several articles and books about business model innovation in networks and Emerging Business Models. He has been researcher at Politechnico di Milano in Italy (2002/03), Stanford University, USA (2010/11), University Tor Vergata, Italy and has in the time period 2007-2010 been the founder and Center Manager of International Center for Innovation www.ici.aau.dk at Aalborg University. He works today as researcher in many different multi business model and technology innovations projects and knowledge networks among others E100 http://www.entovation.com/kleadmap/, Stanford University project Peace Innovation Lab http://captology.stanford.edu/projects/peace-innovation.html, The Nordic Women in business project - www.womeninbusiness.dk/, The Center for TeleInFrastruktur (CTIF) at Aalborg University www.ctif.aau.dk, EU FP7 project about "multi business model innovation in the clouds" www.Neffics.eu. He is co-author to several books. He has an entrepreneurial 
and interdisciplinary approach to research and has initiated several Danish and International research programmes. He is founder of the MBIT lab and is cofounder of CTIF Global Capsule.

His research interests are multi business model and technology innovation in interdisciplinary networks, multi business model typologies, sensing and persuasive business models.

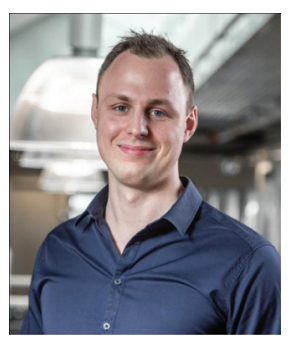

J. Bandsholm is a Scientific Assistent at the Department of Business Development and Innovation at Aarhus University. He holds a M.Sc. in Technology-Based Business Development and has interests in the scientific fields of innovation management, renewable energy and business model innovation. He puts an honor in working in tight collaboration with both public- and private sectors to get to understand and enhance their performance and introducing a new way of approaching innovation - Business Model Innovation. He is currently occupied with his attendance in the nordic Biogas2020 project, where he does different variations of business model innovation, such as network-based business model innovation between multiple partners, networks and ecosystems. 